Pacific Journal of Mathematics

A NOTE ON RADON-NIKODÝM THEOREM FOR FINITELY SURJIT SINGH KHURAN 


\title{
A NOTE ON RADON-NIKODYN THEOREM FOR FINITELY ADDITIVE MEASURES
}

\author{
SURJIT SINGH KhURANA
}

\section{The Radon-Nikodyn theorem for finitely additive measures is deduced from the corresponding result for countably addi- tive measures.}

In ([4], Theorem 1, p. 35) a Radon-Nikodyn type result is proved for finitely additive measures. In this note we prove that this result is a simple consequence of the corresponding result for the countably additive case.

Let $\mathfrak{A}_{0}$ be an algebra of subsets of a set $X$; without loss of generality we assume that $\mathfrak{A}_{0}$ is reduced, i.e., separates points of $X$ ([5], p. 68). We denote by $\rho$ the isomorphism between $\mathfrak{A}_{0}$ and $\mathfrak{A}$ the algebra of all clopen subsets of $\hat{X}$, the compact Hausdorff, totally disconnected space which is the Boolean space for $\mathfrak{A}_{0}$ ([5], p. 70).

TheOREM ([4], Theorem 1, p. 35). Let $\lambda$ and $\mu$ be two complexvalued finite-additive measures on $\mathfrak{A}_{0}$ such that $\mu$ is bounded and $\lambda$ is absolutely continuous relative to $\mu(\varepsilon-\delta$ meaning of absolute continuity). Then there exists a sequence $\left\{f_{n}\right\}$ of $\mathfrak{H}_{0}$-simple functions on $X$ such that

and

(1) $\lim \int_{A} f_{n} d \mu=\lambda(A)$, unif. for $A \in \mathfrak{A}_{0}$

(2) $\lim _{m, n \rightarrow \infty} \int\left|f_{n}-f_{m}\right| d|\mu|=0,|\mu|$ being the total variation of $\mu([2])$.

Proof. For any disjoint sequence $\left\{A_{n}\right\} \subset \mathfrak{A}_{0},|\mu|\left(A_{n}\right) \rightarrow 0$ (note $\mu$ is bounded) and so $\lambda\left(A_{n}\right) \rightarrow 0$. This means $\lambda$ is exhaustive (三strongly bounded) and so $\lambda$ is bounded ([1]). $\lambda$ and $\mu$ naturally give rise to countably additive measures $\lambda^{\prime}$ and $\mu^{\prime}$ on $\mathfrak{A}$ and as such can be uniquely extended to the $\sigma$-algebra $\mathscr{B}_{\infty}$ generated by $\mathfrak{2} ; \mathscr{\mathscr { B }}_{\infty}$ is also the class of all Baire subsets of $\hat{X}\left([5]\right.$, p. 70). We claim $\left|\lambda^{\prime}\right|$ is absolutely continuous with respet to $\left|\mu^{\prime}\right|$ : suppose $\left|\mu^{\prime}\right|(B)=0$ but $\left|\lambda^{\prime}\right|(B)>0$ for some $B \in \mathscr{B}_{\infty}$. This means there exists a $C \subset B, C \in \mathscr{B}_{\infty}$ such that $\left|\lambda^{\prime}(C)\right|>\varepsilon$ for some $\varepsilon>0$. Fix $\delta>0$ such that $P \in \mathfrak{A}_{0}$, $|\mu|(P)<\delta$ implies $|\lambda(P)|<\varepsilon$. Since Baire measures are regular, there exists an open subset $V$ of $\hat{X}$ such that $V \supset C,\left|\mu^{\prime}\right|(V)<\delta$, and $\left|\lambda^{\prime}(V)\right|>\varepsilon$. Again by regularity and total disconnectedness of $\hat{X}$ there is a clopen subset $U \subset V$ such that $\left|\mu^{\prime}\right|(U)<\delta$ and $\left|\lambda^{\prime}(U)\right|>\varepsilon$. Taking $P=\rho^{-1}(U)$ we get $|\mu|(P)<\delta$ and $|\lambda(P)|>\varepsilon$, a contradiction. 
By ([2], Theorem 7, p. 181) theae exists an $f \in \mathscr{L}_{1}\left(X, \mathscr{B}_{\infty},\left|\mu^{\prime}\right|\right)$ such that $\lambda^{\prime}=f \mu^{\prime}$. Since $\mathfrak{A}$-simple functions are dense in $\mathscr{L}_{1}\left(X, \mathscr{B}_{\infty},\left|\mu^{\prime}\right|\right)$ there exists a sequence $\left\{f_{n}\right\}$ of $\mathfrak{A}$-simple functions such that $\lim \int \mid f_{n}-$ $f|d| \mu^{\prime} \mid=0$. From this it follows that $\int_{E} f_{n} d\left|\mu^{\prime}\right| \rightarrow \int_{E} f d\left|\mu^{\prime}\right|$ uniformly for $E \in \mathfrak{A}$. Note on $\mathfrak{A}$ the variation $\left|\mu^{\prime}\right|$ of $\mu^{\prime}$ is the same whether this variation is calculated relative to $\mathfrak{A}$ or $\mathscr{B}_{\infty}([2])$, Theorem $3, \mathrm{p}$. 76). The results (1) and (2) of the theorem are obvious now.

\section{REFERENCES}

1. J. Diestel and B. Faires, On vector measures, Trans. Amer. Math. Soc., 198 (1974), 253-271.

2. N. Dinculeanu, Vector Measures, Pergamon Press, New York, 1967.

3. N. Dunford and J. Schwartz, Linear Operators, Vol. 1, Interscience, New York, 1958.

4. C. Fefferman, A Radon-Nikodyn theorem for finitely additive set function, Pacific J. Math., 23 (1967), 35-45.

5. J. D. M. Wright, The measure extension problem for vector lattices, Ann. Inst. Fourier (Grenoble), 21 (1971), 65-85.

Received July 6, 1977.

UNIVERSITY OF IOWA

IowA City, IA 52242 


\section{PACIFIC JOURNAL OF MATHEMATICS}

\section{EDITORS}

RICHARD ARENS (Managing Editor)

University of California

Los Angeles, California 90024

C. W. Curtis

University of Oregon

Eugene, OR 97403

C. C. MOORE

University of California

Berkeley, CA 94720

\section{J. DUGUNDJI}

Department of Mathematics University of Southern California Los Angeles, California 90007

R. Finn AND J. Milgram Stanford University Stanford, California 94305

ASSOCIATE EDITORS
E. F. BECKENBACH

B. H. NeUMANN

F. WOLF

K. YoshidA

\section{SUPPORTING INSTITUTIONS}

UNIVERSITY OF BRITISH COLUMBIA UNIVERSITY OF SOUTHERN CALIFORNIA CALIFORNIA INSTITUTE OF TECHNOLOGY STANFORD UNIVERSITY UNIVERSITY OF CALIFORNIA MONTANA STATE UNIVERSITY UNIVERSITY OF TOKYO UNIVERSITY OF NEVADA, RENO UNIVERSITY OF UTAH NEW MEXICO STATE UNIVERSITY OREGON STATE UNIVERSITY UNIVERSITY OF OREGON

WASHINGTON STATE UNIVERSITY UNIVERSITY OF WASHINGTON OSAKA UNIVERSITY 


\section{Pacific Journal of Mathematics}

\section{Vol. 74, No. $1 \quad$ May, 1978}

Gerald Arthur Anderson, Computation of the surgery obstruction groups

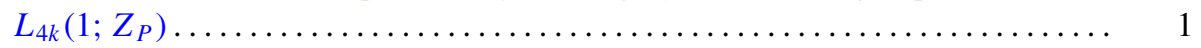

R. K. Beatson, The degree of monotone approximation ................ 5

Sterling K. Berberian, The character space of the algebra of regulated functions . . . 15

Douglas Michael Campbell and Jack Wayne Lamoreaux, Continua in the plane with

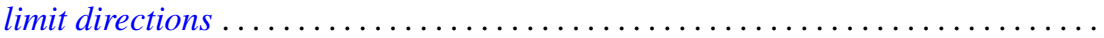

R. J. Duffin, Algorithms for localizing roots of a polynomial and the Pisot

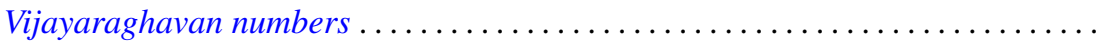

Alessandro Figà-Talamanca and Massimo A. Picardello, Functions that operate on

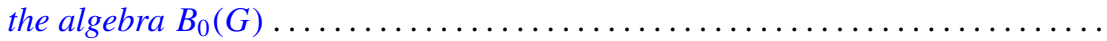

John Erik Fornaess, Biholomorphic mappings between weakly pseudoconvex

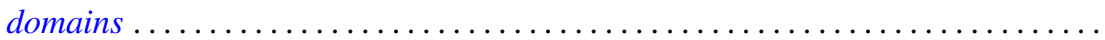

Andrzej Granas, Ronald Bernard Guenther and John Walter Lee, On a theorem of S.

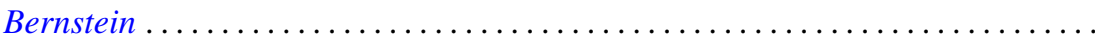

Jerry Grossman, On groups with specified lower central series quotients . .........

William H. Julian, Ray Mines, III and Fred Richman, Algebraic numbers, a constructive development . . . . . . . . . . . . . . . . . . . . . . .

Surjit Singh Khurana, A note on Radon-Nikodým theorem for finitely additive

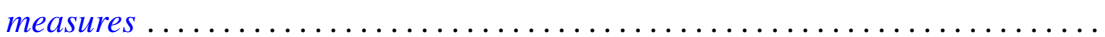

Garo K. Kiremidjian, A Nash-Moser-type implicit function theorem and nonlinear

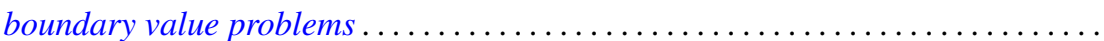

Ronald Jacob Leach, Coefficient estimates for certain multivalent functions ....

John Alan MacBain, Local and global bifurcation from normal eigenvalues. II . . 133

James A. MacDougall and Lowell G. Sweet, Three dimensional homogeneous algebras...

John Rowlay Martin, Fixed point sets of Peano continua ......

R. Daniel Mauldin, The boundedness of the Cantor-Bendixson order of some analytic sets...

Richard C. Metzler, Uniqueness of extensions of positive linear functions ..

Rodney V. Nillsen, Moment sequences obtained from restricted powers . .

Keiji Nishioka, Transcendental constants over the coefficient fields in differential elliptic function fields...

Gabriel Michael Miller Obi, An algebraic closed graph theorem

Richard Cranston Randell, Quotients of complete intersections by $\mathbf{C}^{*}$ actions . . 221

Bruce Reznick, Banach spaces which satisfy linear identities . .

Bennett Setzer, Elliptic curves over complex quadratic fields...

Arne Stray, A scheme for approximating bounded analytic functions on certain subsets of the unit disc.

Nicholas Th. Varopoulos, A remark on functions of bounded mean oscillation and bounded harmonic functions. Addendum to: "BMO functions and the

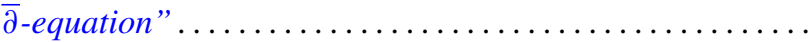

Charles Irvin Vinsonhaler, Torsion free abelian groups quasi-projective over their

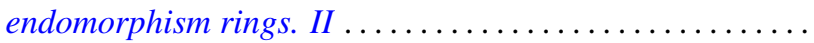

Thomas R. Wolf, Characters of $p^{\prime}$-degree in solvable groups ... 